\title{
Supplier service quality in supply chains of Indian SMEs: A dual direction dyadic perspective
}

\author{
Surjit Kumar Gandhi ${ }^{a^{*}}$, Anish Sachdeva ${ }^{a}$ and Ajay Gupta ${ }^{a}$
}

a Dr. B. R. Ambedkar National Institute of Technology Jalandhar-144 011, Punjab, India

\begin{tabular}{l}
\hline C H R O N I C L E \\
\hline Article history: \\
Received April 12, 2018 \\
Accepted August 82018 \\
Available online \\
August 82018 \\
\hline Keywords: \\
Service Quality \\
Small and medium-sized \\
Enterprises (SMEs) \\
Service quality factors \\
Supplier \\
EFA \\
CFA \\
SEM
\end{tabular}

\section{Introduction}

The fierce competition of today's marketplace is forcing small \& medium-sized enterprises (SMEs) to reshape their strategies in order to curtail overall cost and cut down inefficiencies. Therefore, there is a growing recognition of building and nurturing relationships with supply chain partners for improvements in profitability, serviceability and reduced costs in the supply chain (Kannan \& Tan, 2003). Purchasing is the ultimate goldmine for success to supply-chain enterprises. Because of the mutual benefits they offer (Autry \& Golicic, 2010), partnerships or strategic alliances between suppliers and manufacturers (i.e. buyers) have emerged as a popular business trend (Chen, 2011), and are being looked upon as the wave of the future (Gupta \& Singh, 2017).

Partnership with suppliers is recognized as a major purchasing strategy (Saleh \& Sweis, 2017; Stanley $\&$ Wisner, 2002). Partnership is a source of competitive advantage for both the supplier and the manufacturing unit (Carr et al., 2008). Successful manufacturing organizations leverage on the direct and indirect network of their suppliers to gain competitive advantage (Stanworth, 2012). Some of the typical benefits of suppliers as a manufacturing channel partner can be envisaged as:

\footnotetext{
* Corresponding author

E-mail address: skgandhi21@gmail.com (S. K. Gandhi)
}

(C) 2019 by the authors; licensee Growing Science, Canada doi: $10.5267 /$ j.uscm.2018.8.002 
- Helps in reducing overhead costs through involvement in design, transportation etc.

- Helps the manufacturer to focus on core issues.

- Suppliers with large supply bases can act faster and deliver better quality of material and services.

- Suppliers may add on the service in the form of organizing training programmers, technical services, design inputs, etc. for better service.

- Suppliers with sound financial backups may provide cushioning against fluctuating fund flows.

Managing suppliers is critical to adding value in the supply chain since this function has both intrinsic and extrinsic customers (Seth et al., 2006; Prakash, 2014). Supplier (extrinsic) service quality, SSQ refers to the manner in which staff of the supplier unit serves the requisitions made by manufacturing unit and what attitudes they hold towards the unit. Whereas, Manufacturer (intrinsic) service quality, MSQ refers to the manner in which staff of the manufacturing unit facilitates the functioning of its supplier and what attitudes they hold towards its employees.

In context of SMEs, supplier development is the practice of reducing the number of direct material suppliers and forming strategic alliances with few selected suppliers and devoting resources to increase firm's performance and capabilities (Corsten \& Felde, 2005). In the past, developing inter-firm linkages with suppliers was considered to be uneconomical for manufacturing units because of the large supply bases and distant relationships with suppliers (Gonzalez et al., 2004). Some of the issues regarded critical to supplier relationship management (Gupta et al., 2014; Johnston \& Kristal, 2008; Amad et al., 2008) are as follows:

- Reliance of the manufacturing units on a few dependable suppliers.

- Consideration of quality vs. price tradeoff in selection of suppliers.

- Appropriateness of information provided to suppliers by the manufacturing units.

- Usefulness of the technical assistance provided to suppliers by the manufacturers.

- Involvement of the manufacturer in its suppliers' product development process.

- The manufacturing units entering into long-term contracts with its suppliers.

- Clarity of specifications provided to suppliers by the manufacturers.

Supplier partnership deals with the long-term relationship between the manufacturing unit and its suppliers, and includes make/buy decisions and global sourcing. Small-medium manufacturing units prefer to have few reliable suppliers, and are therefore reducing the number of suppliers, and sometimes relying on a sole source. In an attempt to regain their competitiveness, these units should adopt the Japanese Keiretsu system of manufacturers and suppliers working in lockstep (DeWitt et al., 2006). For supply chain effectiveness, manufacturers and suppliers need to keep costs across the supply chain low so that they result in lower market prices and higher margins. This is akin to gain-sharing arrangements wherein everyone who contributes to greater profitability is rewarded.

The inter-firm linkages between the suppliers and small-medium manufacturing units could relate to product, process, service and market, and through these linkages it is expected that the suppliers will provide necessary support to its SMEs and contribute to the process of creating appropriate technologies. In this backdrop the present research work has been undertaken (Holl, 2008).

Supply chain management is a big umbrella under which suppliers of supplier to end users are there. It consists of all parties which are directly or indirectly involved in fulfilling the customer's request. Everyone is a customer of its upstream so customer focus \& customer satisfaction are the key issues of supply chain management. Viewed from customer's side it is the quality of product, value for money $\&$ post sales facilities. A key feature of present day business is the idea that it is the supply chains that compete, not companies and the success or failure of supply chains is ultimately determined in the 
marketplace by the end user i.e. consumer. As competition moves beyond a single firm into supply chain, focus is shifting from management of internal practice alone (Nix, 2001). Demanding competition in today's global markets, introduction of products with short life cycles, and the discriminating expectations of customers have forced organizations to invest in, and focus attention on supply chains as system which is affected by the environment (Gupta \& Singh, 2015; Lusch et al., 2007; Benton \& Maloni, 2005; Tracey \& Tan, 2001).

SME sector in India, once shielded by the Government policies of reservation, quota and license etc., but the sector is facing a number of challenges to survive due to globalization (Saranga, 2009). Studies on Indian SMEs are largely confined to competitive priorities, manufacturing strategies, capacity building, and innovation trends. The motivation to carry this research is due to following gaps identified in literature.

- There are few studies that have been devoted to the analysis of 'service quality in supply chain' especially with manufacturing which indicates the lack of systematic effort in studying various aspects of service related issues in Indian context.

- Though, there are many qualitative studies on performances measurements (frameworks, guidelines, reviews etc.) but no study has focused on measuring the service quality in a quantitative frame work based on supply chain orientation.

- Much of the research in service quality has focused on exploring relationships between few intangible factors (service quality, satisfaction and loyalty) on different service sectors, except for manufacturing sectors.

- There does not appear a systematic effort to study upstream, organizational and downstream issues to investigate impact of service quality in supply chain.

- Most of the researchers considered only few factors to discuss the service quality. There is no available literature which considers the tangible and intangible factors both to measure the service quality.

- Most of the researchers discussed the various techniques which can be used to compare the factors or some techniques which can be used to find an index value, but none of them have been applied to find the value of service quality in supply chain in manufacturing industry in quantitative form.

Researchers suggest that service quality is positively associated with customer satisfaction (Izogo et al., 2015; Arasli et al., 2005). Studies establish a positive relationship of service quality with customer loyalty (Santouridis et al., 2012; Ganesan, 2007; Ehigie, 2006) too. Service quality is also linked to behavioral outcomes as Word-of-Mouth, complaint, recommending, and switching (Yavas et al., 2004).

In this paper, a focused review of literature was made to develop an instrument for conducting a questionnaire survey. Application of EFA, CFA and SEM brings out a model to answer these questions.

\section{Literature Review}

A close relationship between channel participants shares the risks and rewards and has willingness to maintain the relationship over the long-term (Kaynak, 2003; Cooper \& Ellram, 1993). Carr and Pearson (1999) also found that strong collaborative long-term relationship with key suppliers have a positive influence on the firms' financial performance. Commodity knowledge, cultivation of qualified suppliers, and professionalism were rated as the three most important qualitative criteria (Jun \& Cai, 2010). The continued association with partners enhances service quality of the channel. While there 
have been studies concerning to product quality, very few have worked on facilitating the working of supplier firms in supply chain.

It is well recognized that SMEs lack resources such as, technical, financial, efficient distribution, skilled labor, etc. Lemma et al. (2015) viewed that one way to access these resources is to develop useful horizontal linkages with upstream (supply-related) and downstream (distribution-related) supply chain partners to earn the value from co-operative advantages. Inter-firm linkages can be broadly defined as a process of setting up a continuous business relationship between enterprises in commercially and economically advantageous activities for both parties involved.

Collaboration is a set of management levers that enables cost saving through transfer of best practices, improve effectiveness of decision making through sharing of opinion, induces innovation through cross-pollination of ideas and enhance capacity of collective action (Hansen \& Nohria, 2004). Since much of the value addition occurs in the upstream stages (i.e. supply function) of the supply chain, manufacturers need to manage business-to-business relationships (B2B) with their suppliers. Coordination, collaboration, commitment, communication, trust, flexibility, dependence, joint engineering, and information technology based integration are possible if partners are contributing equal value (Govindan et al., 2010; Wouters et al., 2007). To manage collaborative relationships, it is critical to measure performance on service quality scales. Feedbacks on customer requirements, capabilities of the manufacturing unit and its suppliers, and ongoing collaborations are vital as they reveal the inner working of collaborative processes (Jagdev \& Thoben, 2001).

In order to achieve results in the supply chain, it is critical to address supplier firms' issues through providing a nurturing and proactive work environment, and developing their competencies. By building each other's competencies and promoting a systems thinking can help eliminate functional bottlenecks, develop a process perspective, and direct competencies towards integrative efforts. Leading manufacturing organizations invest in skill up-gradation of supply chain partners by providing on-site training on quality, lean operations, process improvement, and product design (Johnsen, 2009; Grant, 2005). Various issues related to relationship management in supply chain with respect to the supply function are enlisted in table 1. Collaborative relationships characterized by trust and equitable winwin thinking, are the key to successful supply chains (Wu et al., 2010; Rogers et al., 2007).

Though, the output delivered by supplier firm is a well explored area in literature but studies on the applicability of service quality attributes at supplier-manufacturer interface are nascent. Thus there is a major scope for visualizing the attributes of supplier and manufacturer service quality, followed by developing a model to establish their linkages with satisfaction and loyalty.

\section{Table 1}

Relationship Issues at the Supplier-Manufacturer dyad

\begin{tabular}{ll}
\hline Type & Bilateral \\
\hline Characteristics & Strength, Closeness, Physical proximity \\
Dimensions & Coordination, Collaboration, Commitment, Communication, Trust, Flexibility, \\
& Dependence \\
Development & Strategic/ Operational alignment \\
Infrastructure & Partner selection intangible criteria, tangible criteria \\
Information Exchange & Information Systems, Knowledge Transfer \\
\hline
\end{tabular}

Source: Prakash et al., 2011, Pagell et al., 2010, Johnsen, 2009

The study is conducted in exploratory framework using structured interview schedule. The framework shown in Fig. 1 represents the possible relationship among the variables, which will be tested. 


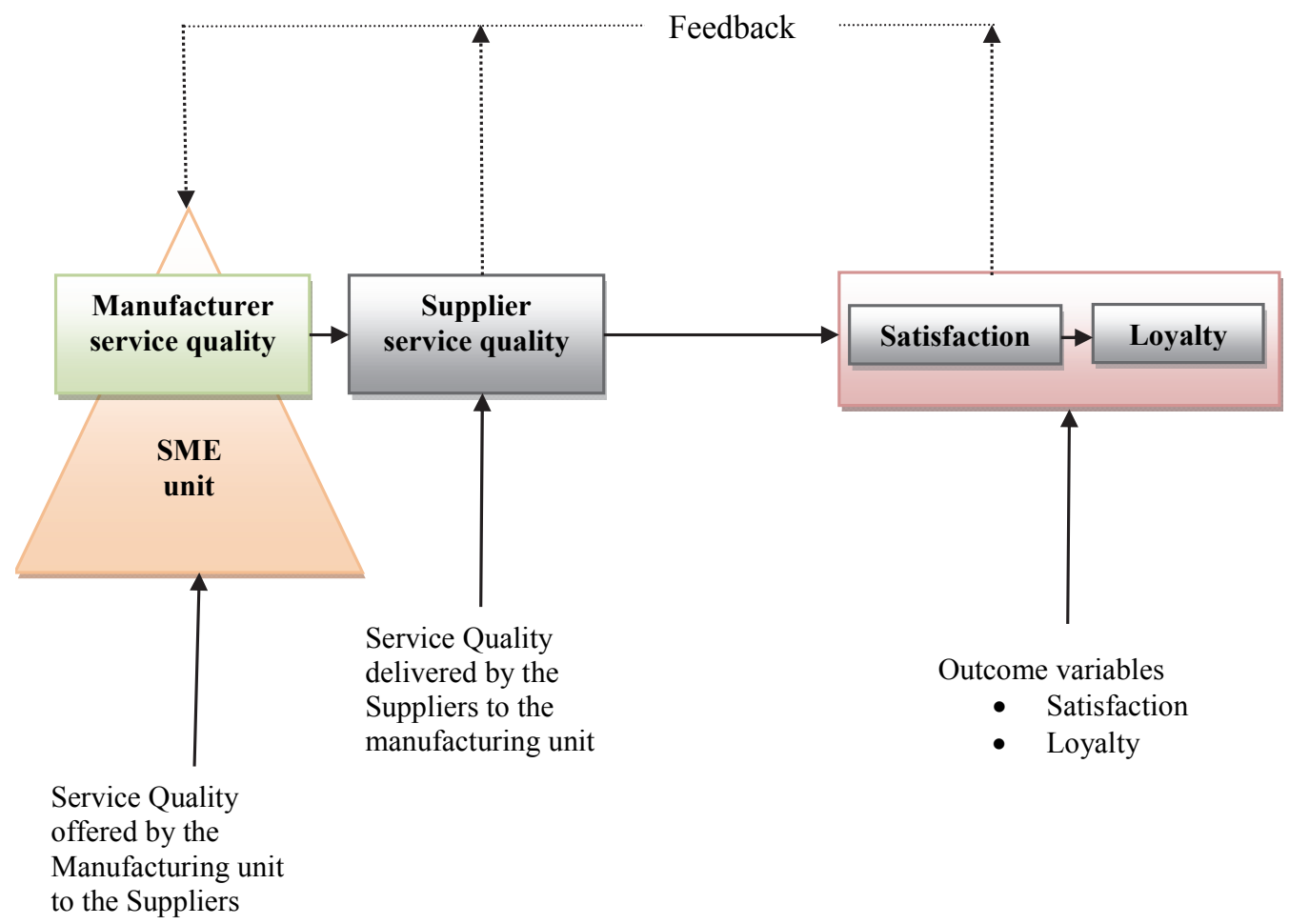

Fig. 1. Conceptual Research Framework

Parasuraman et al. $(1985,1988)$ in their pioneering work identified five components of service quality viz. reliability, assurance, tangibles, empathy, and responsiveness. These five dimensions used to evaluate service quality are called SERVQUAL dimensions. Carr (2007) proposed a major limitation of SERVQUAL scale by stating that it does not consider equity theory for selection of SQ determinants, though it is well established that SME suppliers as well as manufacturers do evaluate service by way of 'fairness' is often evaluated in business encounters.

\section{Service Quality}

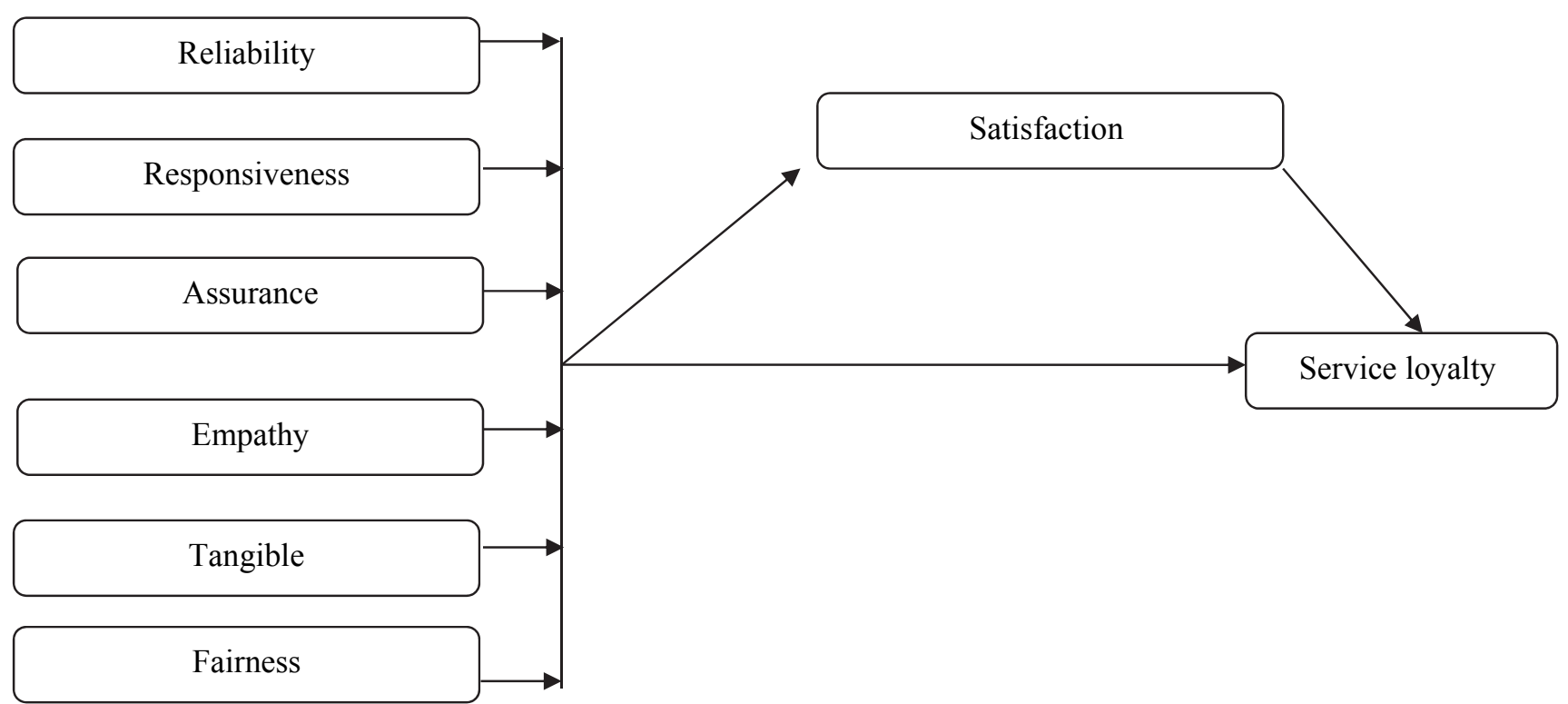

Fig. 2. Relationship between Independent, Mediating and Dependent Variables 
The hybrid scale comprising FAIRSERV (Carr, 2007), in conjunction with SERVQUAL (Parasuraman et al., 1988) is considered suitable for this study, since its outcome parameters are satisfaction and loyalty intensions. The preliminary questionnaire is on five attributes of SERVQUAL scale and "Systematic Fairness" dimension of FAIRSERV model. Taking cues from both existing scales to measure service quality, we have made a modest attempt at designing a new scale based on the combination of the two metrics. Fig. 2 depicts the relationship of the Exogenous, Intervening, and Endogenous variables used in this research.

\section{Research Methodology}

Fig. 3 shows the methodology used for determining factors of manufacturer and supplier service quality followed by establishing their linkages with satisfaction and loyalty. This work is based on studies conducted by Seth et al. (2006) and Prakash (2011).

The questionnaire was generated using with a focus on supply related issues using a combination of SERVQUAL (Parasuraman et al., 1985, 1988) and FAIRSERV (Carr, 2007) scales. It was refined after focus group discussion with five managers working in different SMEs and three academicians with work published in similar area.

The questionnaire thus emerged comprised four sections as follows:

- Section-A comprises 21 items related to service quality offered by the manufacturer towards supplier (MSQ) and 1 item measuring overall manufacturer service quality (OMSQ).

- Section-B consists of 24 items related to service quality delivered by supplier (SSQ) and 1 item measuring overall supplier service quality (OSSQ).

- Section-C consists of two outcome variables viz. satisfaction (mapped by 2 items) and loyalty (mapped by 3 items).

- Section-D focuses focused on gathering the demographic information.

The research methodology is based on empirical data collected through interview schedule. The objective of survey was to examine supplier service quality (internal \& external) in supply chain with relevant data collected from Indian manufacturing small-medium manufacturing units. Research parameters (R-A-T-E-R-F) selected were based on insights gained through literature and extensive field visits as well as exploratory interviews with professionals.

The pilot study was conducted in May-July, 2017. The main survey was conducted from August 2017 to February 2018 by approaching working executives personally and in majority of cases, interviewer himself filling the questionnaire sitting along with them. The advantages of interviewer soliciting the question, details and explanations, an opportunity administer highly complex questionnaires, improved ability to contact hard to reach populations, higher response rates, and increased confidence that data collection instructions are followed (Froza, 2002). This was felt necessary in order to reach response rate of more than 50\% in operations management discipline (Flynn et al. 1990). Kang \& Bradley (2002) also recommended 'in- person distribution and collection method' for improving the response rate.

Some blank questionnaires were also left with some executives with some executive with a request of getting completed from executives known to them. A covering letter describing the objectives the research was also enclosed.

Prior appointments were arranged for explaining and distributing questionnaires majority of cases the responses from the executives were collected on the same day. Sometimes, on the request from the executives, the questionnaires were left with the executive and then collecting personally on the scheduled day. The purpose of this approach was to enhance the response rate and improve the quality of data. 
The method of snowball sampling (Nargundkar, 2003) was used to execute this survey. The respondents were top executives of supplier firms working for small-medium manufacturing units located in North India. Respondents were asked to respond their perceptions of service quality that was being offered to them by manufacturing units manufacturing units on 5-point Likert scale. The researcher approached 165 respondents serving in different small-medium manufacturing units and was able to elicit data from 120 respondents, thus fetching a response rate of $73 \%$ which was quite satisfactory. Majority of the respondents belonged to the top management of unit including Proprietors, MDs, Unit Heads, Chief Works Managers, GMs, Sales Managers, Logistics In-charge, Executive Engineers, Heads of different departments \& sections etc.

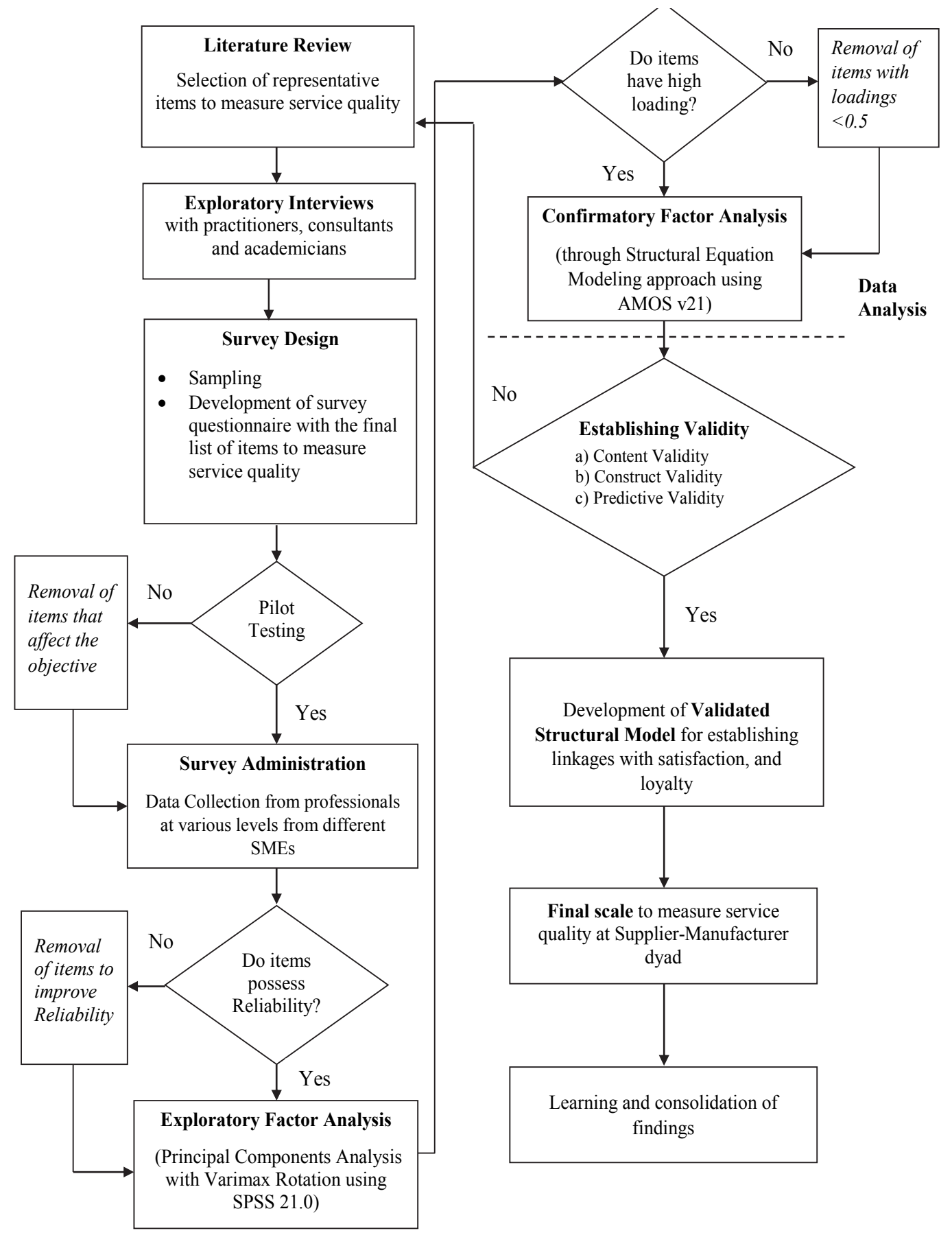

Fig. 3. Flow chart of research methodology adopted for measurement and modeling of service quality at Supplier-Manufacturer interface 
The type of manufacturing activity being carried by the respondent units is shown in table 2 .

Table 2

Type of product being manufactured by respondent units $(\mathrm{N}=120)$

\begin{tabular}{lcc}
\hline Type of Manufacturing Unit & Small Scale & Medium Scale \\
\hline Number \& Percentage & $87(73 \%)$ & $33(27 \%)$ \\
Type of Product & & \\
Auto Parts & $26(\approx 22 \%)$ & $9(\approx 8 \%)$ \\
Hand Tools & $15(\approx 13 \%)$ & $5(\approx 4 \%)$ \\
Casting Components & $12(\approx 10 \%)$ & $4(\approx 3 \%)$ \\
Valve manufacturing & $9(\approx 8 \%)$ & $4(\approx 3 \%)$ \\
Rolled Products & $6(\approx 5 \%)$ & $4(\approx 3 \%)$ \\
Machine Tools & $6(\approx 5 \%)$ & $3(\approx 2 \%)$ \\
Sheet Metal Components & $5(\approx 4 \%)$ & $2(\approx 2 \%)$ \\
Fasteners & $4(\approx 3 \%)$ & $2(\approx 2 \%)$ \\
Multi Products & $4(\approx 3 \%)$ & Nil \\
\hline
\end{tabular}

The demographic distribution of respondents is presented in Table 3. The respondents have been categorized on the basis of number of years of experience, qualifications, and functional area of work.

\section{Table 3}

Demographic distribution of respondents $(\mathrm{N}=120)$

\begin{tabular}{lccccclcc}
\hline \multicolumn{2}{c}{ Experience } & \multicolumn{3}{c}{ Qualification } & \multicolumn{3}{c}{ Functional Area of work } \\
\hline \multicolumn{1}{c}{ Distribution } & $\mathrm{n}$ & $\%$ & \multicolumn{1}{c}{ Distribution } & $\mathrm{n}$ & $\%$ & \multicolumn{1}{c}{ Department } & $\mathrm{n}$ & $\%$ \\
\hline 2- 5 years & 42 & 35 & MBA/M.Tech./M.Sc. & 16 & 13 & Procurement & 48 & 40 \\
6-10 years & 24 & 20 & BBA/B.Tech./B.Sc. & 43 & 36 & Inventory/Store & 28 & 23 \\
11-15 years & 26 & 22 & MA/BA/B.Com. & 24 & 20 & Marketing/Sales & 20 & 17 \\
16-20 years & 16 & 13 & Technical Diploma & 22 & 18 & Production & 14 & 12 \\
above 20 years & 12 & 10 & Intermediate/below & 15 & 13 & Quality Control & 10 & 08 \\
\hline
\end{tabular}

We find that most of the respondents have work experience in the range 2 to 10 years, hold engineering qualification, and work in the areas of personnel management.

\section{Data Analysis}

Since the factors of the scale along with indicators used to measure MSQ and SSQ are synthesized from the literature, the imperative is first to assess the scales for reliability, EFA and CFA.

\subsection{Reliability Analysis}

The reliability of both MSQ and SSQ scales was analyzed using Cronbach alpha coefficient (Cronin \& Taylor 1992; Lee et al., 2000) using IBM SPSS v21 and the output is depicted in table 4.

\section{Table 4}

Reliability Analysis of items in MSQ and SSQ scale

\begin{tabular}{lcc}
\hline Service Quality Measurement & MSQ items $(\mathrm{n}=21)$ & SSQ items $(\mathrm{n}=24)$ \\
\hline Value of $\boldsymbol{\alpha}$ & 0.926 & 0.897 \\
Finding & Quite Good (Nunnally \& Bernstein, 1978). \\
\hline
\end{tabular}

\subsection{Exploratory Factor Analysis (EFA)}

EFA is a multivariate statistical technique commonly used to explore the dimensionality of a measurement. The IBM SPSS v21 was used for this purpose. The main objective of using EFA in this paper is to group the factors into various sub-groups for making further analysis simpler. Prior to application of EFA, Bartlett test of Sphericity is used to verify appropriateness of factor analysis (Hair 
et al., 2010). To check whether the sample size is adequate or not, Kaiser-Meyer-Olkin (KMO) test of sample adequacy $(\mathrm{N}=120$, in this case) and significance value was performed. The value of KMO greater than 0.6 with the value for significance less than 0.005 , indicate data size is sufficient for grouping the various relevant factors (Tabachnick \& Fidell, 2007). The score of Bartlett test of sphericity and the KMO value is depicted in Table 5.

\section{Table 5}

KMO and Bartlett's Test of Sphericity

\begin{tabular}{lccc}
\hline KMO Measure for Sampling Adequacy & & MSQ scale & SSQ scale \\
\cline { 2 - 4 } & & .888 & .880 \\
\hline \multirow{3}{*}{ Bartlett's Test of Sphericity } & 2101 & 2101 & 2221 \\
& 210 & 210 & 231 \\
& .000 & .000 & .000 \\
\hline
\end{tabular}

The results being significant, indicate the suitability for factor analysis (Hair et al., 2010).

EFA conducted using the Principle Component Analysis (PCA) with Kaiser Normalization (Eigen values greater than 1) and varimax rotation procedure resulted in the extraction of five factors each for MSQ and SSQ scale, explaining 74.802 and 73.301 per cent of the variance respectively. These factor loadings are consistent with the suggested factor structure of the scale. Output of exploratory factor analysis using SPSS v21 is presented in Table 6 and Table 7.

Table 6

Communalities, Factor Structure and Loadings for Items of MSQ

\begin{tabular}{|c|c|c|c|c|c|c|}
\hline \multirow{2}{*}{$\begin{array}{l}\text { S. No. } \\
\text { Assuranc }\end{array}$} & \multirow{2}{*}{$\begin{array}{l}\text { Factors and Associated Items } \\
\text { ce }\end{array}$} & \multirow[t]{2}{*}{ Communalities } & \multicolumn{4}{|c|}{ Factor Structure and loadings } \\
\hline & & & & & & \\
\hline 1. & Long term collaborative relationship & .859 & .879 & & & \\
\hline 2. & Purchase orders are timely and accurate & .851 & .881 & & & \\
\hline 3. & Has modern and adequate physical facilities & .851 & .882 & & & \\
\hline 4. & Possesses right tools and equipment & .821 & .890 & & & \\
\hline 5. & Terms \& conditions are fair with supplier & .735 & .822 & & & \\
\hline 6. & Confidentiality in transactions & .698 & 699 & & & \\
\hline \multicolumn{7}{|c|}{ Communication } \\
\hline 7. & $\begin{array}{l}\text { Honest in providing information/ financial } \\
\text { data }\end{array}$ & .792 & & .854 & & \\
\hline 8. & $\begin{array}{l}\text { Pays attention to suppliers' views in } \\
\text { dealings }\end{array}$ & .540 & & .667 & & \\
\hline 9. & Shares information related to inventory & .647 & & .756 & & \\
\hline & Inform changes in manufacturing schedule & .760 & & .833 & & \\
\hline & Prompt feedback about quality of products & .816 & & .853 & & \\
\hline & Have latest IT infrastructure & .635 & & .761 & & \\
\hline \multicolumn{7}{|c|}{ Alignment } \\
\hline 13. & Flexible approach in dealing with suppliers & .693 & & & .736 & \\
\hline 14. & $\begin{array}{l}\text { Shares company's future plans with } \\
\text { suppliers }\end{array}$ & .819 & & & .820 & \\
\hline 15. & Equitable sharing of responsibilities & .803 & & & .811 & \\
\hline 16. & Shares knowledge/training/innovation base & .863 & & & .852 & \\
\hline 17. & $\begin{array}{l}\text { Based at convenient \& approachable } \\
\text { location }\end{array}$ & .865 & & & .869 & \\
\hline \multicolumn{7}{|c|}{ Responsiveness } \\
\hline 18. & Willingness to share supplier problems & .698 & & & & .814 \\
\hline 19. & $\begin{array}{l}\text { Supplier's queries are heard \& solved } \\
\text { promptly }\end{array}$ & .604 & & & & .735 \\
\hline 20. & Respect and positive attitude for supplier & .730 & & & & .828 \\
\hline 21. & Values convenience of suppliers & 630 & & & & .714 \\
\hline Reliabi & ity (Cronbach Alpha Value) of identified fa & tors & .947 & .911 & .939 & .814 \\
\hline
\end{tabular}


As shown in above Table 6, the extracted factors were named as: Assurance, Communication, Alignment, and Responsiveness. All the items have significant communalities (not less than 0.50) (Hair et al., 2010) and significant factor loadings (not less than 0.55) (Pitt et al., 1995). Internal reliability of the items of the various factors of the MSQ scale is examined using the Cronbach alpha coefficients (Bagozzi \& Yi, 1988). In this analysis, reliability score for each factor ranges from $81.4 \%$ to $94.7 \%$ as shown in Table 6 and hence is acceptable (Nunnally \& Bernstein, 1978).

Likewise on the SSQ scale, the five factors were named as: Credibility, Relationship, Alignment, Understanding, and Dependability. All the items have significant communalities and factor loadings. The reliability score for each factor ranges from $83.6 \%$ to $95.1 \%$ as shown in table 7 and hence is acceptable.

\section{Table 7}

Communalities, Factor Structure and Loadings for Items of SSQ Scale

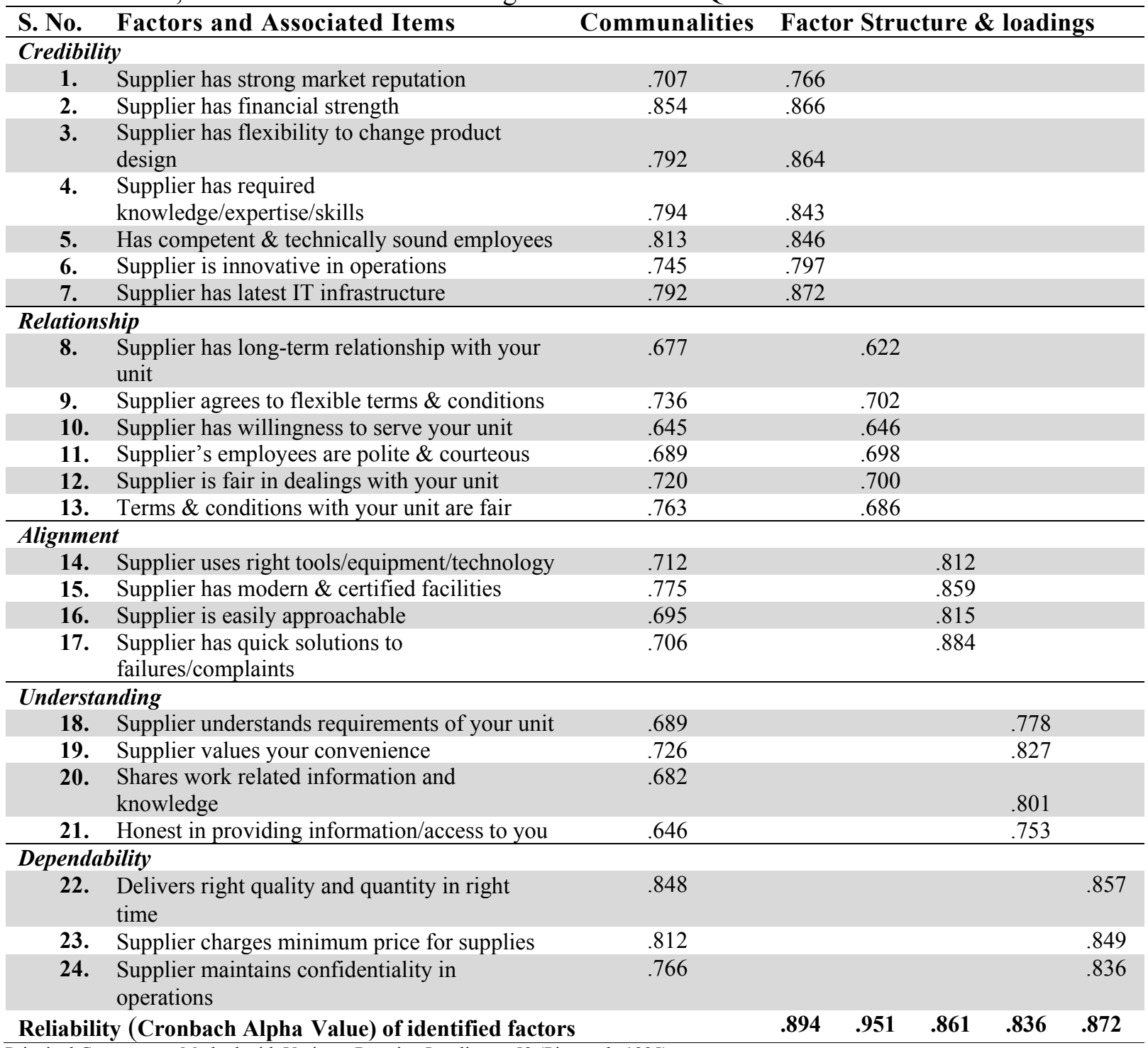




\subsection{Confirmatory Factor Analysis (CFA)}

CFA is undertaken to further validate the scales for measuring MSQ and SSQ. CFA model is run using SPSS AMOS v21, for 4 individual factors describing MSQ scale and 5 factors describing SSQ scale, with respective items. Table 8 shows the key model fit indices for the individual factors.

Table 8

Key fit Indices for measurement model of MSQ and SSQ scale

\begin{tabular}{lcccccc}
\hline MSQ scale & & & & & & \\
\hline \multicolumn{1}{c}{ Factors } & Cmin/df & RMR & GFI & NFI & CFI & RMSEA \\
\hline Assurance & 1.346 & .009 & .982 & .991 & .998 & .054 \\
Communication & 1.337 & .024 & .970 & .978 & .994 & .053 \\
Alignment & .760 & .008 & .990 & .994 & 1.000 & .000 \\
Responsiveness & .367 & .012 & .997 & .995 & 1.000 & .000 \\
\hline SSQ scale & & & & & & \\
$\quad$ Factors & Cmin/df & RMR & GFI & NFI & CFI & RMSEA \\
\hline Credibility & .496 & .007 & .987 & .994 & 1.000 & .000 \\
Relationship & .968 & .018 & .982 & 1.000 & 1.000 & .000 \\
Alignment & 3.232 & .018 & .974 & .972 & .980 & .037 \\
Understanding & .529 & .013 & .996 & .994 & 1.000 & .000 \\
Dependability & --- & .000 & 1.000 & 1.000 & 1.000 & -- \\
\hline
\end{tabular}

Since all the GFI values are greater than 0.9 , the validation of individual factors of CFA models is established (Hair et al., 2010).

\subsection{CFA matrix development and scale purification}

\subsubsection{CFA matrix development for MSQ and SSQ scale}

In order to develop the measurement scale, the covariance matrices between the four factors identified for MSQ scale and five factors identified for SSQ scale was created as shown in Fig. 4 and Fig. 5.
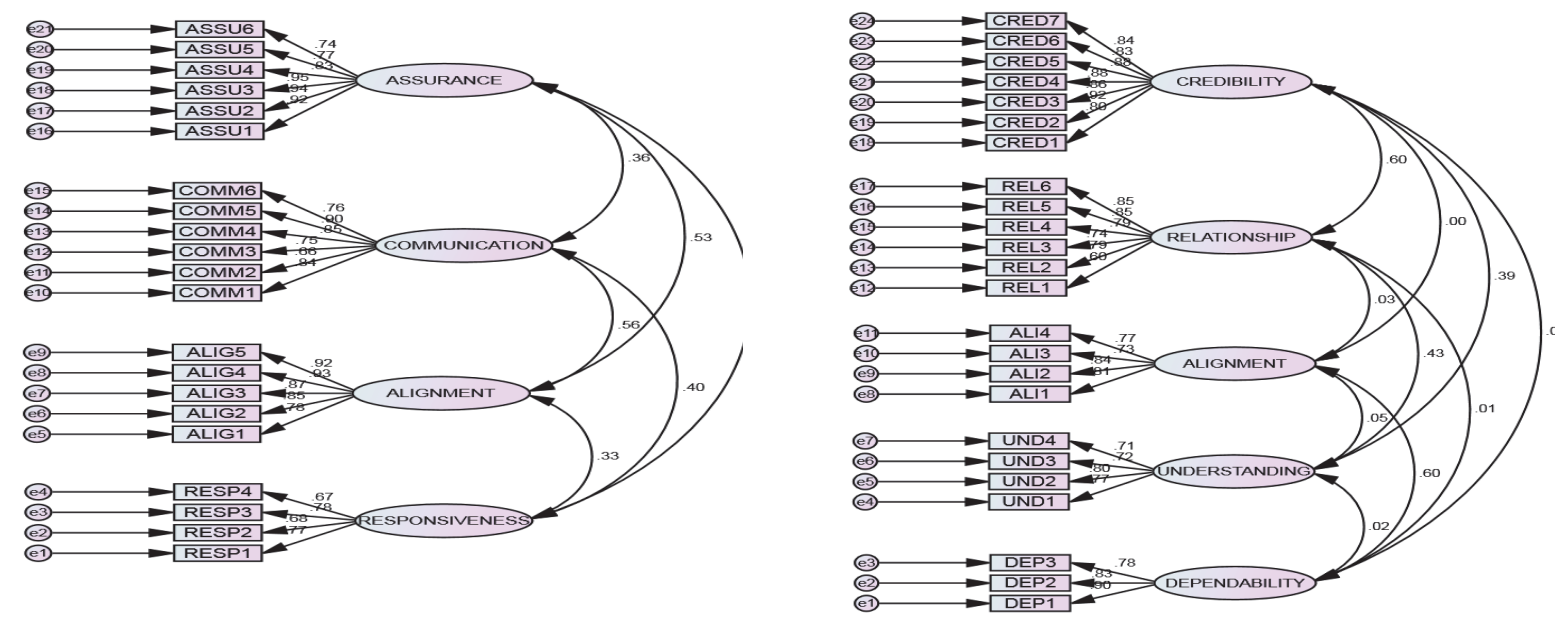

Fig. 4. Theoretical framework for development of MSQ Scale

Fig. 5. Theoretical framework for development of SSQ Scale 


\subsubsection{CFA matrix purification for MSQ and SSQ scale}

For purification of MSQ scale, three iterations runs of CFA were performed to obtain satisfactory goodness of fit indices. During this process, 5 items out of initial 21 items were deleted due to low explained variance. The five items were:

i. $\quad$ the manufacturing unit maintains confidentiality in transactions;

ii. the unit possesses the latest information technology infrastructure;

iii. the unit pays attention to suppliers' views in dealings;

iv. the unit has an equitable sharing of responsibilities with the supplier firm; and

v. the unit is based at convenient \& approachable location.

The final model consisting of four attributes and 16 unique sub-factors is depicted in Fig. 6.

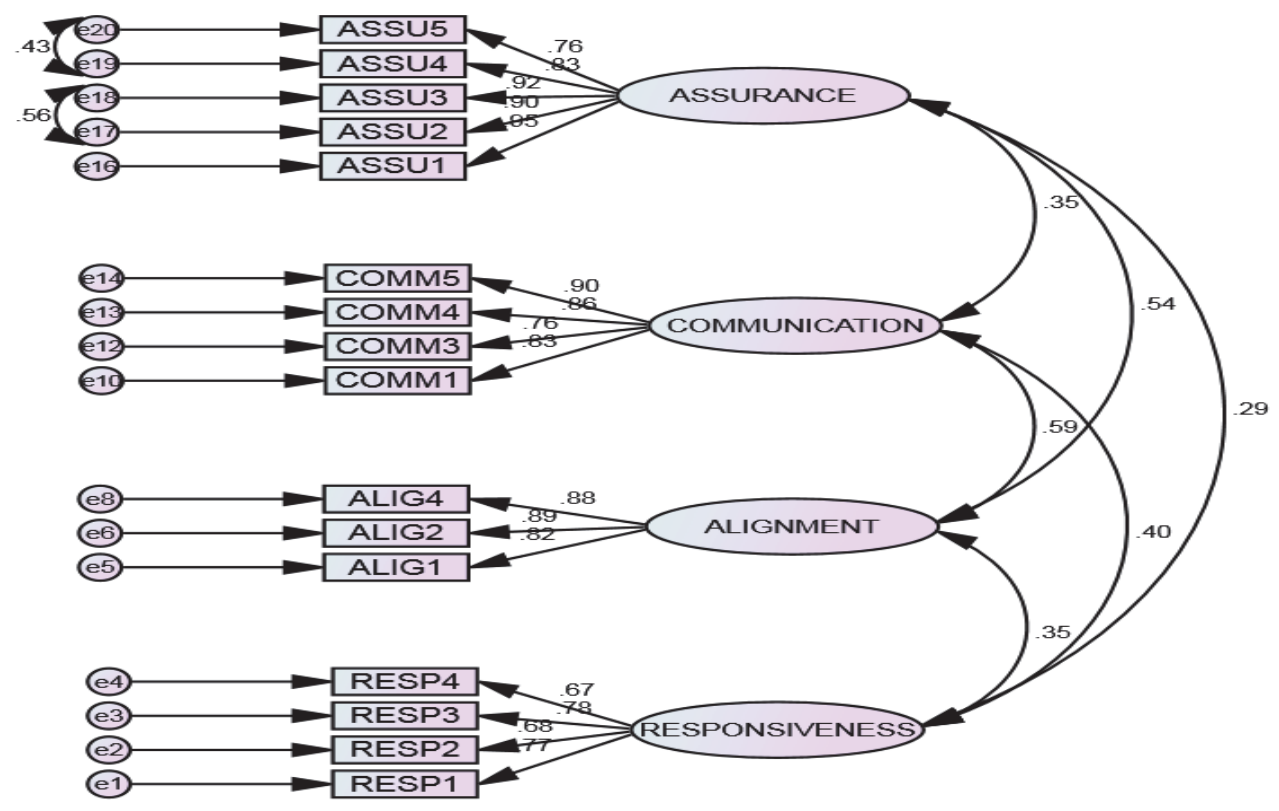

Fig. 6. CFA Model Development for measuring MSQ

Various goodness-of-fit indices are obtained by running the model using AMOS v 21. The Normed Chi-square value for this model is 0.993 , which represents a good fit. The acceptable ratio of Normed Chi-square value is up to 3 or even 5 (Hooper et al., 2008; Hox \& Bechger, 1998). The Goodness-ofFit Index (GFI), the Comparative-Fit-Index (CFI) and the Normed-Fit-Index (NFI) values for this model were $0.913,1.000$, and 0.937 respectively. The RMSEA value of 0.000 indicates a perfect fit. From these values it is inferred that model represents an adequate fit.

Likewise for SSQ scale, five iterations runs of CFA were performed to obtain satisfactory goodness of fit indices. During this process, one dimension viz. Alignment, was completely dropped. In total, 11 out of an initial 24 items were deleted owing to low variance. The deleted items were:

i. the supplier has financial strength

ii. the supplier has required knowledge/expertise/skills

iii. the supplier firm has latest infrastructure;

iv. the supplier has willingness to serve your unit

v. the supplier is fair in dealings with your unit 
vi. terms \& conditions with the unit are reasonable

vii. the supplier uses right tools/equipment/technology

viii. the supplier has modern \& certified facilities

ix. the supplier is easily approachable

$\mathrm{x}$. the supplier has quick solutions to failures/complaints

xi. the supplier maintains confidentiality in operations

The final model consisting of 4 factors and 13 sub-factors is depicted in Fig. 7.

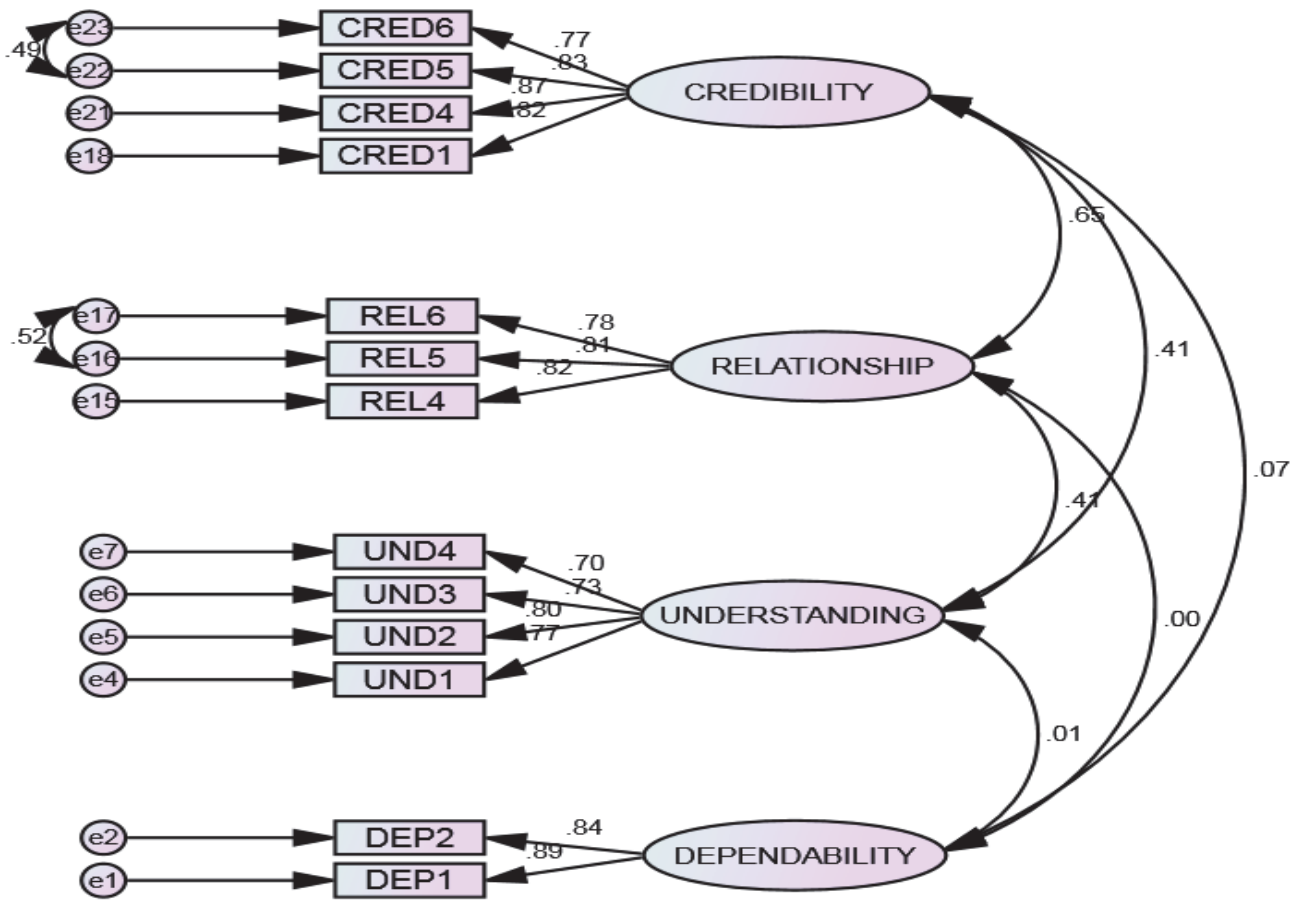

Fig. 7. CFA Model Development for measuring SSQ

The Normed Chi-square value for this model is 1.342, which represents a good fit. The GFI, CFI, and NFI values for this model were $0.911,0.977$, and 0.918 respectively. The RMSEA value of 0.054 indicates a reasonable fit. From these values it is inferred that model represents an adequate fit.

\section{Conceptual Model and Analysis}

The following two models have been conceptualized:

Model-I to examine the impact of Manufacturer service quality on Supplier service quality, $>$ Model-II to examine the impact of Supplier service quality on Satisfaction, and Loyalty.

\subsection{Model-I}

This model is conceptualized to evaluate the impact of MSQ on SSQ. Fig. 8 depicts schematic diagram of structural relationship between exogenous latent variable MSQ and endogenous latent variable SSQ using factors of the scales as identified by EFA followed by CFA. 


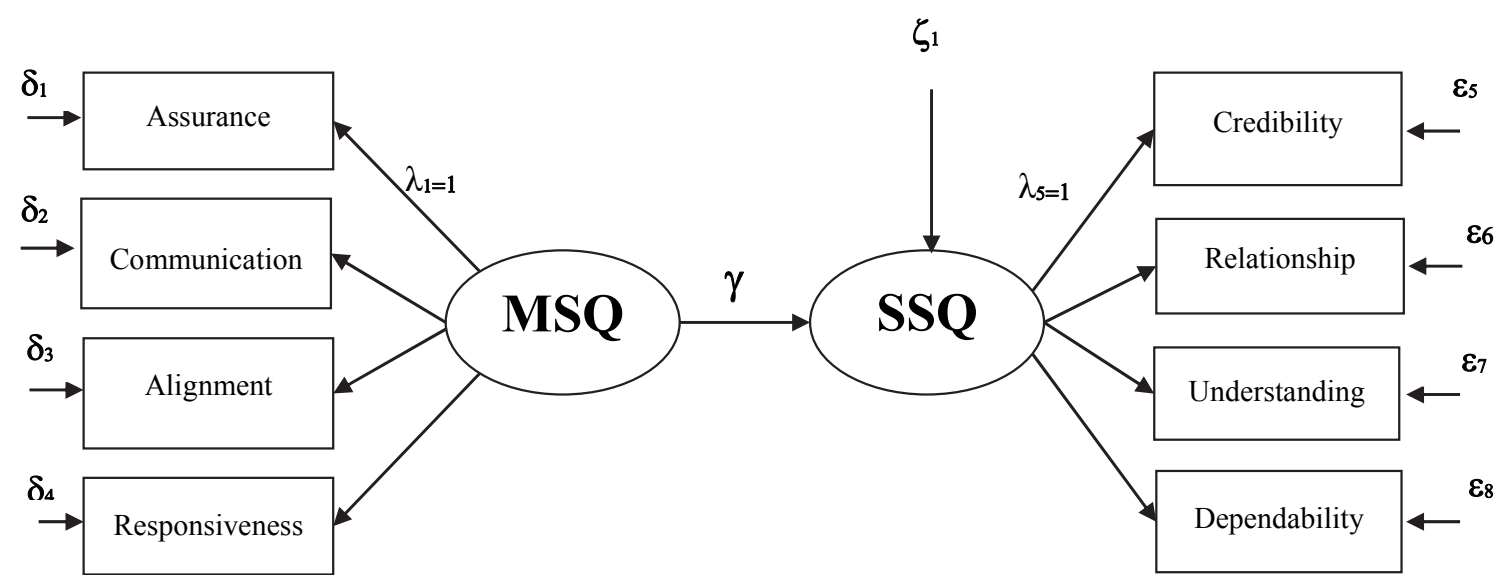

Fig. 8. Conceptual Model representing the relationship between MSQ and SSQ

\section{Notations:}

$\lambda$ : Factor loadings in measurement part of MSQ/SSQ

$\delta$ : Residual errors in measurement part of MSQ

$\gamma$ : Path Coefficient from MSQ to SSQ

$\varepsilon$ : Residual errors in measurement part of SSQ

$\zeta:$ Residual error in SSQ

\subsubsection{Analysis of Model-I}

Proposition 1: Manufacturer service quality is a source of Supplier service quality. The following hypothesis is developed for testing this relationship:

\begin{tabular}{lll}
\hline S. No. & Null Hypothesis $\left(\mathbf{H}_{\mathbf{0}}\right)$ & Alternative Hypothesis (Ha) \\
\hline $\mathrm{H}_{1}$ & $\begin{array}{l}\text { Path coefficient } \gamma \text { is not significantly different } \\
\text { form } 0 .\end{array}$ & $\begin{array}{l}\text { Manufacturer service quality is positively } \\
\text { linked to supplier service quality. }\end{array}$ \\
\hline
\end{tabular}

\subsubsection{Model Fit}

Various goodness-of-fit indices are obtained by running the model using AMOS v21. The Normed Chisquare value for this model is 1.657 , which represents a good fit. The GFI, CFI, and NFI values for this model were $0.945,0.977$, and 0.944 respectively. The RMSR value of 0.027 and RMSEA value of 0.074 also indicates a reasonable fit. Fig. 9 depicts the pictorial representation of various path estimates of the model-I.

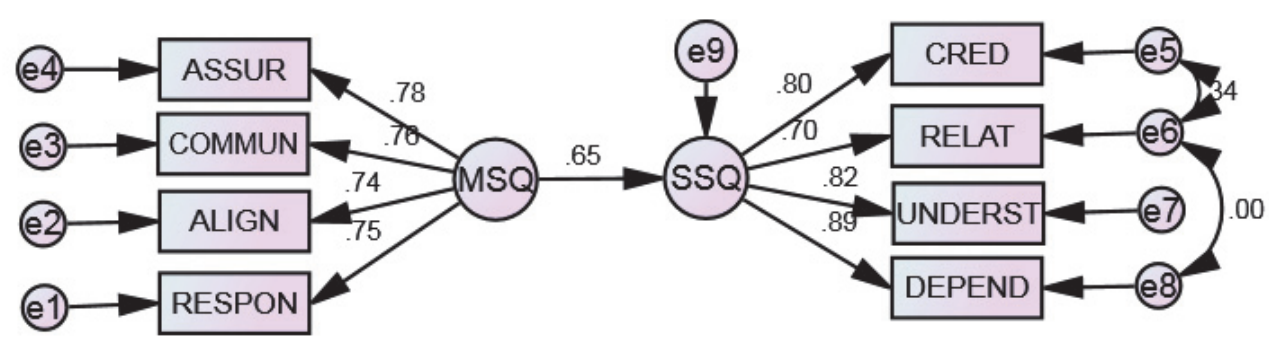

Fig. 9. Path estimates of Model-I 
Various path estimates between exogenous and endogenous latent variables of the model-I are depicted in Table 9. All the regression weights were significant which is in line with the hypothesized relationships.

\section{Table 9}

Regression Weights for Model-I

\begin{tabular}{lc}
\hline \multicolumn{1}{c}{ Path } & Standardized Regression Weight Estimate \\
\hline MSQ to SSQ & 0.65 \\
MSQ to Assurance & $\mathbf{0 . 7 8}$ \\
MSQ to Communication & 0.76 \\
MSQ to Alignment & 0.74 \\
MSQ to Responsiveness & 0.75 \\
SSQ to Credibility & 0.80 \\
SSQ to Relationship & 0.70 \\
SSQ to Understanding & 0.82 \\
SSQ to Dependability & $\mathbf{0 . 8 9}$ \\
\hline
\end{tabular}

The regression weight for the Assurance dimension was highest for manufacturer service quality (MSQ) towards supplier, whereas the regression weight for Dependability was highest for measuring supplier service quality (SSQ) in such units. The Standardized Regression Weight for the path linking exogenous latent variable manufacturer service quality to endogenous latent variable supplier service quality was 0.65 which was found to be significant at a significance level of $5 \%$. Therefore, the alternative hypothesis $\mathrm{H}_{\mathrm{a}}$ of MSQ positively impacting the SSQ is accepted.

\subsection{Model-II}

The model-II is conceptualized to understand the relationship between MSQ and SSQ with satisfaction and loyalty at manufacturing unit-supplier interface. The conceptual structural model for this relationship is depicted in Fig. 10.

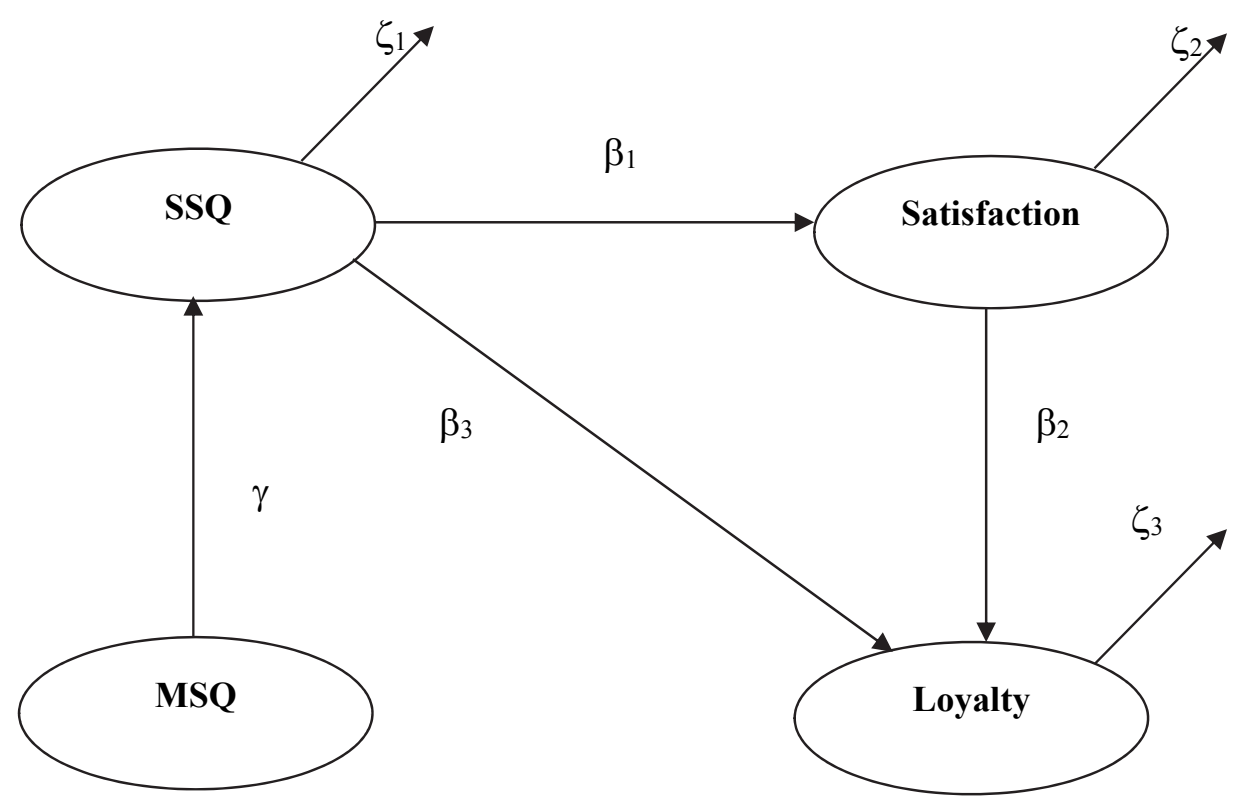

Fig. 10. Conceptual Structural Model-II 


\section{Notations:}

$\gamma:$ Path Coefficient from MSQ $\rightarrow$ SSQ

$\beta_{1}, \beta_{2}, \beta_{3}$ : Path Coefficients from SSQ $\rightarrow$ Satisfaction; Satisfaction $\rightarrow$ Loyalty, SSQ $\rightarrow$ Loyalty, resp.

$\zeta_{1}, \zeta_{2}, \zeta_{3}:$ Residual error in measurement of SSQ, Satisfaction, and Loyalty respectively

\subsubsection{Analysis of Model-II}

Proposition 2: Supplier service quality is a source of Satisfaction.

Proposition 3: Satisfaction is a source of Loyalty.

Proposition 4: Supplier service quality is a source of Loyalty.

The following hypotheses are developed for testing this relationship:

\begin{tabular}{cll}
\hline S. No. & Null Hypothesis $\left(\mathbf{H}_{\mathbf{0}}\right)$ & Alternative Hypothesis (Ha) \\
\hline $\mathbf{H}_{2}$ & $\begin{array}{l}\mathrm{H}_{0} \text { 2: Path coefficient } \beta_{1} \text { is not significantly } \\
\text { different from } 0 .\end{array}$ & $\mathrm{H}_{\mathrm{a}}$ 2: SSQ is positively linked to Satisfaction. \\
$\mathbf{H}_{3}$ & $\begin{array}{l}\mathrm{H}_{0} 3 \text { : Path coefficient } \beta_{2} \text { is not significantly } \\
\text { different from } 0 .\end{array}$ & $\begin{array}{l}\mathrm{H}_{\mathrm{a}} 3 \text { : Satisfaction from the supplier is positively } \\
\text { linked to Loyalty. }\end{array}$ \\
$\mathbf{H}_{\mathbf{4}}$ & $\begin{array}{l}\mathrm{H}_{0} 4 \text { : Path coefficient } \beta_{3} \text { is not significantly } \\
\text { different from } 0 .\end{array}$ & $\mathrm{H}_{\mathrm{a}} 4:$ SSQ is positively linked to Loyalty. \\
\hline
\end{tabular}

\subsubsection{Model Fit}

Various goodness-of-fit indices are obtained by running the model using AMOS v21. The Normed Chisquare value for this model is 1.607 , which represents a good fit. The GFI, CFI, and NFI values for this model were $0.941,0.946$, and 0.978 respectively. The RMSR value of 0.070 and RMSEA value of 0.071 indicate a reasonable fit.

Fig. 11 depicts the pictorial representation of various path estimates of the model-II.

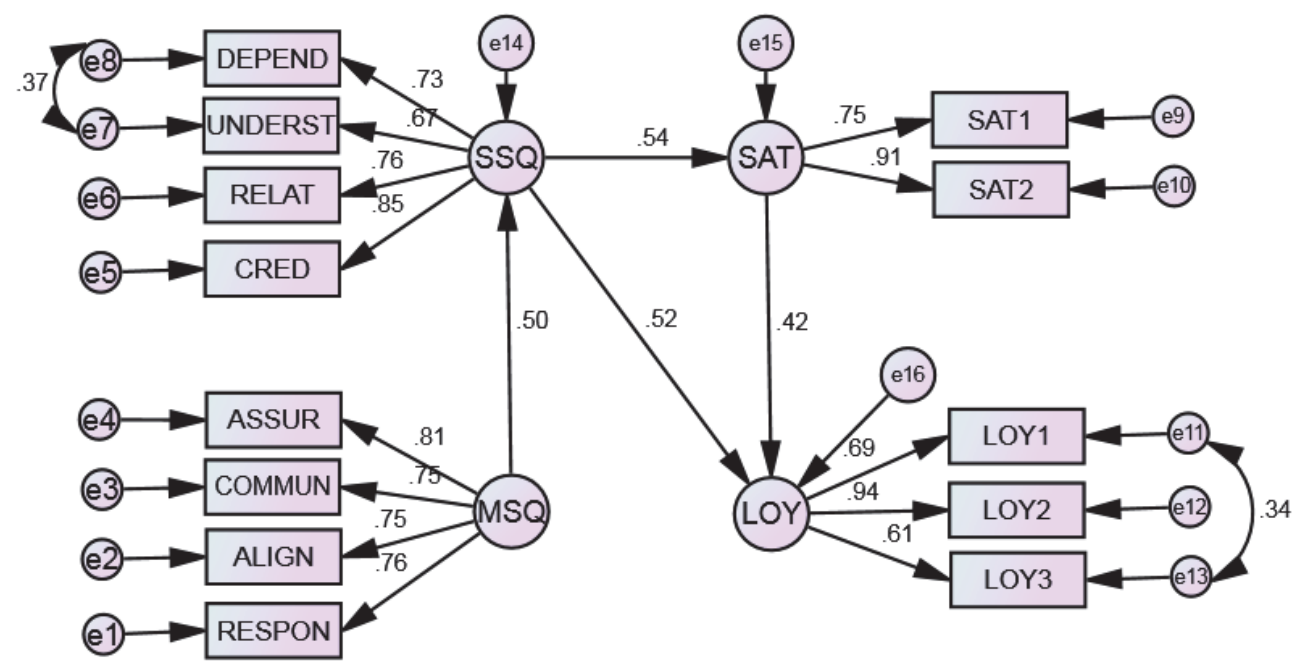

Fig. 11. Path estimates of Model-II

Various path estimates among latent variables of the model-II are depicted in table 10. The positive signs of the parameters representing the paths between the latent variables are in line with hypothesized relationships. 
Table 10

Results for Structural Relationship in the Model-II

\begin{tabular}{llll}
\hline Path & Estimate & t value* $^{*}$ & Conclusion \\
\hline SSQ to Satisfaction & 0.54 & 6.178 & Supported \\
SSQ to Loyalty & 0.52 & 3.568 & Supported \\
Satisfaction to Loyalty & 0.42 & 3.770 & Supported \\
\hline
\end{tabular}

$*-1.96<\mathrm{t}<1.96$ indicate that parameter is not significantly different from zero at $5 \%$ level of significance.

The Standardized Regression Weight for the path linking SSQ to Satisfaction was 0.54 which was found to be significant at a significance level of .05. Therefore, the alternative hypothesis $\mathrm{H}_{\mathrm{a}} 2$ of Supplier service quality (i.e., service quality delivered by the supplier) positively impacting the Satisfaction of manufacturer is accepted.

The Standardized Regression Weight for the path linking Satisfaction to Loyalty was 0.42 which was found to be significant at a significance level of $5 \%$. Therefore, the alternative hypothesis $\mathrm{H}_{\mathrm{a}} 3$ of Satisfaction perceived by manufacturer from the services delivered by Supplier positively impacting the Loyalty is accepted.

The Standardized Regression Weight for the path linking SSQ to Loyalty was 0.52 which was found to be significant at a significance level of 5\%. Therefore, the alternative hypothesis $\mathrm{H}_{\mathrm{a}} 4$ of $S S Q$ positively impacting the Loyalty is accepted.

\section{Conclusions}

The present study was intended to study a) Service quality offered by the manufacturing unit (MSQ) towards facilitation of working of its supplier; b) Supplier service quality (SSQ) delivered by supplier; and c) the relationship of these constructs i.e. MSQ and SSQ with satisfaction and loyalty measures. The insights provided by this study can help managers and researchers in further understanding the service quality issues relating to the supply function in SMEs. This paper also comes out with a set of four hypotheses as enumerated in previous section at supplier-manufacturer interface. Some of the typical benefits of the proposed scales are as follows:

i. The proposed structure fills the gaps that exist in the conceptualization of service quality issues related to purchasing and supply functions in small-medium enterprises of emerging economies like India. The study brings out useful determinants (four each) to measure both MSQ and SSQ. The scores on individual sub-dimensions indicate suggestions for improvements to managers along those areas.

ii. The MSQ and SSQ scales can also be used as diagnostic tools for identifying poor and/or excellent performance to benchmark across multiple departments within a single manufacturing unit. Furthermore, any of these situations can also be compared across time.

iii. The study also derived linkages between $M S Q$ and $S S Q$ with satisfaction and loyalty based on structural equation modeling. Operations improve process and design quality, reduce waste, fine-tune internal processes and develop synchronized linkages with suppliers and distributors, and thereby achieve operational efficiencies. By way of cost reduction and increase in product and service reliability, these operational efficiencies improve the attractiveness of the products and services. In the market, improved service quality enhances satisfaction and loyalty of suppliers, and lures them away from competitors who are perceived low in service quality.

iv. Thus, to achieve loyalty, it is vital for supply chain stakeholders to coordinate, synchronize and integrate their activities to produce desired outputs by incorporating service quality initiatives. 
However, these findings can be extended to add distributor, retailer and end user's perspective. Traditionally, service quality driven operations have been overlooked in such units with an understanding that transaction specific opportunistic approach may work best for SMEs.

Mohanty et al. (2014) argue that in the supply of raw materials, the quality of service is a major factor in competition. This may be more relevant in the SME clusters where manufacturers produce intrinsically similar products. This study demonstrates that high service quality is increasingly important as a tool which is used by the supplier towards their manufacturers. The service quality provided by the supplier and manufacturer to each other helps in establishing close relationships. Close relationships are important in creating mutual commitment and understanding. Various empirical studies on the supply function demonstrate that satisfaction is derived from relationships between the supplier and the manufacturer. The findings of this study are in line those of other scholars who report that satisfaction results from satisfaction with products and services (Prakash et al., 2014) and satisfaction with various facets of the manufacturing organization (i.e., manufacturers) such as financial or social aspects (Sanzo et al., 2003).

In order to compete globally, these units need to benchmark themselves against quality standards and practices of small manufacturers in countries such as USA, the European Union, and Japan. Nevertheless, in their quest for excellence, these units should evolve at a fast pace, and shift from rigid traditional structure to more responsive and customer-centric business models, replacing vertical business process with horizontal business processes so as to increase organizational and process flexibility, and sharing information with their stake-holders and coordinate processes leading to effective and timely decision making and responsiveness to customer needs.

In a nutshell, the honest sharing of operational information, integrating supply chain strategy, promptness in handling queries or failures, meeting deadlines, maintaining secrecy in dealings, flexibility in terms and conditions as per requirements, and preference for long-term collaborative relationship are few attributes that need to be incorporated at various supplier-manufacturer dyad of the supply chain.

At this point it is essential to offer a caveat that some scholars have suggested that SME managers, instead of building relationships with suppliers, still adhere to practices such as competition between suppliers to drive down prices, and weeding out suppliers who do not provide competitive prices (Amad et al., 2008). Grant (2005) has suggested that in the case of logistics based services, there is often a dichotomy in what manufacturers say that they consider as desirable (relationship with supplier), and what they actually practice (transaction-specific behavior). However, this dichotomy has so far not been resolved in this study.

\section{Limitations of the Study}

In this research, an attempt was made to study and evaluate supplier service quality in supply chain. Supplier Service quality is a main concern in supply chain and provides a useful framework to explore consequences of service quality for the upstream chain and reports a strong significance. Limitations of this study are as follows:

1. Though large number of factor has been considered for evaluation, some external factors like legal, political etc. not considered.

2. Factors for this study have been identified from the available literature which published in various reputed journals. There are chances that more research articles can be cited which are not included in the present research.

3. This study is based on the collection of data with the opinion of experts, hence there is a chance of biasing. 
4. The data collection is for manufacturing supply chain only.

5. This study used survey method which was restricted to North India, while application of this methodology in other regions may change the predict result of this study.

\section{Scope for Future Research}

There are always chances of improvements in every work or research. Following are the expected scope for future work:

- The data collection approach used in the present study was snow ball sampling method, other sampling methods may be adopted for the same purpose.

- As EFA, CFA, and SEM were used to evaluate the service quality in present study, some other MADM technique may be used for the same purpose.

- This study was restricted to northern region of India, other regions of India may be considered for the same study.

- Some more number of factors may be identified for each drives of supply chain.

- The study considered supplier supply chain in this study in a manufacturing chain, others supply chains may be considered.

\section{References}

Amad, L. C., Hamid, A. B. A., Salleh, N. M., \& Choy, C. S. (2008). Adapting buyer-supplier relationship practices in the local industry. Asian Academy of Management Journal, 13(2).

Arasli, H., Mehtap-Smadi, S., \& Turan Katircioglu, S. (2005). Customer service quality in the Greek Cypriot banking industry. Managing Service Quality: An International Journal, 15(1), 41-56.

Autry, C. W., \& Golicic, S. L. (2010). Evaluating buyer-supplier relationship-performance spirals: A longitudinal study. Journal of Operations Management, 28(2), 87-100.

Bagozzi, R. P., \& Yi, Y. (1988). On the evaluation of structural equation models. Journal of the academy of marketing science, 16(1), 74-94.

Benton, W. C., \& Maloni, M. (2005). The influence of power driven buyer/seller relationships on supply chain satisfaction. Journal of Operations Management, 23(1), 1-22.

Carr, A. S., \& Pearson, J. N. (1999). Strategically managed buyer-supplier relationships and performance outcomes. Journal of operations management, 17(5), 497-519.

Carr, A. S., Kaynak, H., Hartley, J. L., \& Ross, A. (2008). Supplier dependence: impact on supplier's participation and performance. International Journal of Operations \& Production Management, 28(9), 899-916.

Carr, C. L. (2007). The FAIRSERV model: Consumer reactions to services based on a multidimensional evaluation of service fairness. Decision Sciences, 38(1), 107-130.

Chen, Y. J. (2011). Structured methodology for supplier selection and evaluation in a supply chain. Information Sciences, 181(9), 1651-1670.

Cooper, M. C., \& Ellram, L. M. (1993). Characteristics of supply chain management and the implications for purchasing and logistics strategy. The International Journal of Logistics Management, 4(2), 13-24.

Corsten, D., \& Felde, J. (2005). Exploring the performance effects of key-supplier collaboration: an empirical investigation into Swiss buyer-supplier relationships. International Journal of Physical Distribution \& Logistics Management, 35(6), 445-461.

Cronin Jr, J. J., \& Taylor, S. A. (1992). Measuring service quality: a reexamination and extension. The journal of marketing, 55-68.

DeWitt, T., Giunipero, L. C., \& Melton, H. L. (2006). Clusters and supply chain management: the Amish experience. International Journal of Physical Distribution \& Logistics Management, 36(4), 289-308. 
Ehigie, O. B. (2006). Correlates of customer loyalty to their bank: a case study in Nigeria. International Journal of Bank Marketing, 24(7), 494-508.

Flynn, B. B., Sakakibara, S., Schroeder, R. G., Bates, K. A., \& Flynn, E. J. (1990). Empirical research methods in operations management. Journal of operations management, 9(2), 250-284.

Ganesan, P. (2007). Service Quality, Customer Satisfaction and Loyalty: Indian Public Sector Bank's Branch Level Study. Panda TK and Donthu N Marketing in the New Global Order: Challenges and Opportunities.

Gonzalez, M. E., Quesada, G., \& Mora Monge, C. A. (2004). Determining the importance of the supplier selection process in manufacturing: a case study. International Journal of Physical Distribution \& Logistics Management, 34(6), 492-504.

Govindan, K., Kannan, D., \& Noorul Haq, A. (2010). Analyzing supplier development criteria for an automobile industry. Industrial Management \& Data Systems, 110(1), 43-62.

Grant, D. B. (2005). The transaction-relationship dichotomy in logistics and supply chain management. In Supply Chain Forum: An International Journal, 6(2), 38-48.

Gupta, M., Choudhary, A. K., \& Alam, M. S. (2014). Effect of trust, satisfaction and other relationship dimensions on supplier relationship management. Review of Integrative Business and Economics Research, 3(2), 17.

Gupta, T. K., \& Singh, V. (2015). A systematic approach to evaluate supply chain management environment index using graph theoretic approach. International Journal of Logistics Systems and Management, 21(1), 1-45.

Gupta, T. K., \& Singh, V. (2017). Measurement of service quality of automobile organisation by artificial neural network. International Journal of Management Concepts and Philosophy, 10(1), 32-53.

Hair Jr, J. F., Black, W. C., Babin, B. J., Anderson, R. E., \& Tatham, R. L. (2010). SEM: An introduction. Multivariate data analysis: A global perspective, 629-686.

Hansen, M. T., \& Nohria, N. (2004). How to build collaborative advantage. MIT Sloan Management Review, 46(1), 22.

Holl, A. (2008). Production subcontracting and location. Regional Science and Urban Economics, 38(3), 299-309.

Hooper, D., Coughlan, J., \& Mullen, M. (2008). Structural equation modelling: Guidelines for determining model fit. Articles, 2.

Hox, J. J., \& Bechger, T. M. (1998). An introduction to structural equation modeling.

Izogo, E. E., \& Ogba, I. E. (2015). Service quality, customer satisfaction and loyalty in automobile repair services sector. International Journal of Quality \& Reliability Management, 32(3), 250-269.

Jagdev, H. S., \& Thoben, K. D. (2001). Anatomy of enterprise collaborations. Production planning \& control, 12(5), 437-451.

Johnsen, T. E. (2009). Supplier involvement in new product development and innovation: Taking stock and looking to the future. Journal of Purchasing and Supply Management, 15(3), 187-197.

Johnston, D. A., \& Murat Kristal, M. (2008). The climate for co-operation: buyer-supplier beliefs and behavior. International Journal of Operations \& Production Management, 28(9), 875-898.

Jun, M., \& Cai, S. (2010). Examining the relationships between internal service quality and its dimensions, and internal customer satisfaction. Total Quality Management, 21(2), 205-223.

Kang, H., \& Bradley, G. (2002). Measuring the performance of IT services: An assessment of SERVQUAL. International Journal of Accounting Information Systems, 3(3), 151-164.

Kannan, V. R., \& Choon Tan, K. (2003). Attitudes of US and European managers to supplier selection and assessment and implications for business performance. Benchmarking: An international journal, 10(5), 472-489.

Kaynak, H. (2003). The relationship between total quality management practices and their effects on firm performance. Journal of operations management, 21(4), 405-435.

Lee, H., Lee, Y., \& Yoo, D. (2000). The determinants of perceived service quality and its relationship with satisfaction. Journal of services marketing, 14(3), 217-231. 
Lemma, H. R., Singh, R., \& Kaur, N. (2015). Determinants of supply chain coordination of milk and dairy industries in Ethiopia: a case of Addis Ababa and its surroundings. Springer Plus, 4(1), 498.

Lusch, R. F., Vargo, S. L., \& O’brien, M. (2007). Competing through service: Insights from servicedominant logic. Journal of retailing, 83(1), 5-18.

Mohanty, M. K., Gahan, P., \& Choudhury, S. (2014). Why most of the supplier development programs fail in discrete manufacturing-findings from selected Indian discrete manufacturing industries. International Journal of Management Science and Engineering Management, 9(3), 201211.

Nargundkar, R. (2003). Marketing research-Text \& cases 2E. Tata McGraw-Hill Education.

Nix, N. (2001). Customer service in supply chain management context. Supply Chain Management, CA: Sage Publications, Beverly Hills.

Nunnally, J. C., \& Bernstein, I. H. (1978). Psychometric theory.

Pagell, M., Wu, Z., \& Wasserman, M. E. (2010). Thinking differently about purchasing portfolios: an assessment of sustainable sourcing. Journal of Supply Chain Management, 46(1), 57-73.

Parasuraman, A., Zeithaml, V. A., \& Berry, L. L. (1985). A conceptual model of service quality and its implications for future research. The Journal of Marketing, 41-50.

Parasuraman, A., Zeithaml, V. A., \& Berry, L. L. (1988). SERVQUAL: A multiple-item scale for measuring consumer perception of service quality, Journal of retailing, 64(1), 12.

Pitt, L. F., Watson, R. T., \& Kavan, C. B. (1995). Service quality: a measure of information systems effectiveness. MIS quarterly, 173-187.

Prakash, G. (2011). Service quality in supply chain: empirical evidence from Indian automotive industry. Supply Chain Management: An International Journal, 16(5), 362-378.

Prakash, G. (2014). QoS in the internal supply chain: the next lever of competitive advantage and organisational performance. Production Planning \& Control, 25(7), 572-591.

Rogers, K. W., Purdy, L., Safayeni, F., \& Duimering, P. R. (2007). A supplier development program: rational process or institutional image construction?. Journal of Operations Management, 25(2), 556-572.

Saleh, R. A., \& Sweis, R. J. (2017). The relationships between soft/hard total quality management practices and operational performance in Jordanian manufacturing organisations. International Journal of Management Concepts and Philosophy, 10(4), 345-377.

Santouridis, I., Trivellas, P., \& Tsimonis, G. (2012). Using ES-QUAL to measure internet service quality of e-commerce web sites in Greece. International Journal of Quality and Service Sciences, 4(1), 86-98.

Sanzo, M. J., Santos, M. L., Vázquez, R., \& Álvarez, L. I. (2003). The effect of market orientation on buyer-seller relationship satisfaction. Industrial Marketing Management, 32(4), 327-345.

Saranga, H. (2009). The Indian auto component industry-Estimation of operational efficiency and its determinants using DEA. European Journal of Operational Research, 196(2), 707-718.

Seth, N., Deshmukh, S. G., \& Vrat, P. (2006). SSQSC: a tool to measure supplier service quality in supply chain. Production planning \& control, 17(5), 448-463.

Stanley, L. L., \& Wisner, J. D. (2002). The determinants of service quality: issues for purchasing. European Journal of purchasing \& Supply management, 8(2), 97-109.

Stanworth, J. O. (2012). Deep supply relationships: influencing outcomes by managing supply service quality. Production Planning \& Control, 23(7), 541-552.

Tabachnick, B. G., \& Fidell, L. S. (2007). Using multivariate statistics. Allyn \& Bacon/Pearson Education.

Tracey, M., \& Leng Tan, C. (2001). Empirical analysis of supplier selection and involvement, customer satisfaction, and firm performance. Supply Chain Management: An International Journal, 6(4), 174188.

Wouters, M., van Jarwaarde, E., \& Groen, B. (2007). Supplier development and cost management in Southeast Asia-Results from a field study. Journal of Purchasing and Supply Management, 13(4), 228-244. 
Wu, Z., Choi, T. Y., \& Rungtusanatham, M. J. (2010). Supplier-supplier relationships in buyersupplier-supplier triads: Implications for supplier performance. Journal of Operations Management, 28(2), 115-123.

Yavas, U., Benkenstein, M., \& Stuhldreier, U. (2004). Relationships between service quality and behavioral outcomes: A study of private bank customers in Germany. International Journal of Bank Marketing, 22(2), 144-157.

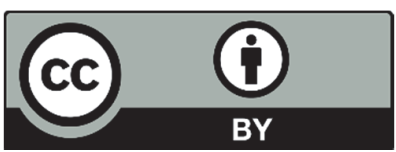

(C) 2018 by the authors; licensee Growing Science, Canada. This is an open access article distributed under the terms and conditions of the Creative Commons Attribution (CC-BY) license (http://creativecommons.org/licenses/by/4.0/). 